\title{
Aplikasi Pendukung Keputusan Pupuk Non Subsisdi Dengan Metode String Matching (Studi Kasus Cv. Family Groups Labuhanbatu Selatan)
}

\author{
Muhammad Siddik ${ }^{1}$, Syaiful Zuhri Harahap ${ }^{2}$ \\ ${ }^{1}$ STIKOM Pelita Indonesia, Pekanbaru, Indonesia \\ ${ }^{2}$ Universitas Labuhanbatu, Rantauprapat, Indonesia
}

\begin{tabular}{l} 
Info Artikel \\
\hline Article history: \\
Received: 21122018 \\
Revised: 13012019 \\
Accepted: 28012019 \\
Kata Kunci: \\
SPK \\
String Matching \\
Pupuk Non Subsidi \\
Penulis Korespondensi: \\
Muhammad Siddik \\
siddik@lecturer.pelitaindonesia.ac.id
\end{tabular}

\begin{abstract}
Utilization of computer-based information systems within a company is expected to be able to manage company data properly in order to reduce the level of errors that occur, such as data recording, data storage, data retrieval, and reporting. As well as an inventory data processing application system in a goods distributor company, which includes sales, purchases, and delivery of goods. Nonsubsidized fertilizer inventory data processing at CV. South Labuhanbatu Family Groups are still manual, meaning that in terms of recording and processing, they still use notes in books. In searching data is done manually by checking one by one the existing and stored documents are not arranged based on a specific code, thus complicating the search for data / documents.
\end{abstract}

\begin{abstract}
Abstrak
Pemanfaatan sistem informasi berbasis komputer di dalam suatu perusahaan diharapkan mampu untuk mengelola data-data perusahaan dengan baik agar dapat mengurangi tingkat kesahalan yang terjadi, seperti pencatatan data, penyimpanan data, pencarian data, dan pembuatan laporan. Seperti halnya sistem aplikasi pengolahan data persediaan dalam suatu perusahaan distributor barang, yang mana didalamnya mencakup penjualan, pembelian, dan pengiriman barang. Pengolahan data inventory pupuk non subsidi di CV. Family Groups Labuhanbatu Selatan masih manual, artinya dari segi pencatatan dan pengolahannya masih menggunakan catatan di buku. Dalam Pencarian data dilakukan secara manual dengan cara memeriksa satu-persatu dokumen yang ada dan disimpan tidak tersusun berdasarkan kode tertentu, sehingga mempersulit pencarian data/dokumen.
\end{abstract}

\section{PENDAHULUAN}

Perkembangan dan kebutuhan akan teknologi informasi yang pesat pada saat sekarang ini, terutama dalam dunia bisnis, menciptakan peluang serta ancaman bagi perusahaan untuk terus berkembang.[1] Hal ini juga yang menyebabkan munculnya kemajuan pada perangkat lunak dan diimbangi pula dengan kemajuan pada perangkat kerasnya.[2] Secara langsung ataupun tidak, teknologi informasi telah menjadi bagian penting dari berbagai bidang kehidupan. Salah satunya pada proses kegiatan bisnis yang dilakukan perusahaan.Kegiatan bisnis saat ini diharuskan dapat mengolah data dengan tepat sekaligus mampu menghemat waktu pada saat proses transaksi berlangsung.[3] Pemanfaatan sistem informasi berbasis komputer di dalam suatu perusahaan diharapkan mampu untuk mengelola data-data perusahaan dengan baik agar dapat mengurangi tingkat kesahalan yang terjadi, seperti pencatatan data, penyimpanan data, pencarian data, dan pembuatan laporan. Seperti halnya sistem aplikasi pengolahan data persediaan dalam suatu perusahaan distributor barang, yang mana didalamnya mencakup penjualan, pembelian, dan pengiriman barang.[5] 


\section{TINJAUAN TEORI \\ 1. Perancangan}

Menurut McLeod (2007 ,p238) perancangan sistem adalah penentuan proses dan data yang diperlukan oleh sistem baru, jika sistem itu berbasis komputer, [6]perancangan dapat dinyatakan spesifikasi peralatan yang digunakan. Menurut Mardi MSI (2011,p124) menjelaskan bahwa pengembangan sistem idealnya dilaksanakan dalam suatu kerangka rancangan induk sistem yang mengkoordinasikan proyek pengembangan sistem kedalam rancangan strategis perusahaan.. [7] Menurut Jogiyanto (1999:179) perancangan mempunyai 2 maksud, yaitu untuk memenuhi kebutuhan kepada pemakai sistem dan untuk memberikan gambaran yang jelas kepada pemogram komputer dan ahli-ahli teknik lainnya yang terlibat.[8] Perancangan menurut Al-Bahra Bin Ladjamudin (2005:39) dalam bukunya yang berjudul Analisis dan Desain Sistem Informasi, adalah sebagai berikut: "Tahapan perancangan (design) memiliki 59 tujuan untuk mendesain sistem baru yang dapat menyelesaikan masalah masalah yang dihadapi perusahaan yang diperoleh dari pemilihan alternatif sistem yang terbaik". (Mariana Purba, M.Kom, 2017).[9] Menurut Jogiyanto (1999:179) perancangan mempunyai 2 maksud, yaitu untuk memenuhi kebutuhan kepada pemakai sistem dan untuk memberikan gambaran yang jelas kepada pemrogram komputer dan ahli-ahli teknik lainnya yang terlibat.[10] Sistem Menurut Scott (1996) sistem terdiri dari unsur-unsur seperti masukan (input), pengolahan (processing), keluaran (output)(Hanif Al Fatta 2007:4). Menurut McLeod (2004) sistem adalah sekelompok elemen-elemen yang terintegrasi dengan tujuan yang sama untuk mencapai tujuan.[11]

Sedangkan menurut Jogiyanto (1999) terdapat dua kelompok pendekatan sistem didalam mendefinisikan sistem yaitu pendekatan pada prosedur dimana sistem adalah suatu jaringan kerja dari prosedur-prosedur yang saling berhubungan,[12] terkumpul bersama-sama untuk melakukan suatu kegiatan atau untuk tujuan tertentu, dan pendekatan pada komponenkomponen atau elemen-elemen, pendekatan pada komponen dianggap lebih mudah dalam mepelajari sistem untuk tujuan dan perancangan system (Yakub, 2012:1). [13]Sebuah sistem terdiri dari berbagai unsur yang saling melengkapi dalam mencapai tujuan dan sasaran. Unsur-unsur yang terdapat dalam sistem itulah yang disebut dengan subsistem. Subsistem- subsistem tersebut harus saling berhubungan dan berinteraksi melalui komunikasi yang relevan sehingga sistem dapat bekerja secara efektif dan efisien.[14]

\section{Sistem Informasi}

Jogiyanto (1999) Sistem informasi adalah suatu sistem di dalam suatu organisasi yang mempertemukan kebutuhan pengolahan data transaksi harian, mendukung operasi, bersifat manajerial, dan kegiatan strategi dari suatu organisasi serta menyediakan pihak luar tertentu dengan laporan-laporan yang diperlukan (Yakub, 2012:17).[15] Menurut Robert A. Leitch (1983:6) Sistem Informasi adalah suatu sistem di dalam suatu organisasi yang mempertemukan kebutuhan pengolahan transaksi harian, mendukung operasi, bersifat manajerial dan kegiatan srategis dari suatu organisasi dan menyediakan pihak luar tertentu dengan laporanlaporan yang diperlukan.[16] Sistem Informasi merupakan suatu system di dalam suatu organisasi yang merupakan kombinasi dari orang- orang, fasilitas, teknologi, media, prosedur-prosedur dan pengendalian (Jogiyanto:1985:14).[17]

\section{Sistem Pendukung Keputusan}

Sistem pendukung keputusan adalah sebuah himpunan/kumpulan prosedur berbasis model untuk memproses data dan pertimbangan untuk membantu manajemen dalam pembuatan keputusannya (Little , 1970). [6]Sistem pendukung keputusan sebagai sekumpulan tools komputer yang terintegrasi yang mengijinkan seorang decision maker untuk berinteraksi langsung dengan komputer untuk menciptakan informasi yang berguna dalam membuat keputusan semi terstruktur dan keputusan tak terstruktur yang tidak terantisipasi (Hick ,1993)[8].

\section{HASIL PENELITIAN DAN PEMBAHASAN}

\section{Hasil Analisa}

CV. FAMILY GRUB dalam menentukan KEPUTUSAN PUPUK NON SUBSIDI secara keseluruhan sistem nya belum terkomputerisasi. Maka dilakukan analisis permasalahan sebagai langkah awal setelah mengalisis permasalahan kemudian data hasil penelitian yang telah diperoleh dan dikelompokkan menurut jenis sumber datanya, kemudian dianalisa lebih lanjut. Sebelum melakukan pembuatan sebuah aplikasi perangkat lunak, dilakukan suatu perancangan akan perangkat lunak tersebut. 


\section{Hasil Perancangan}

Dalam perancangan pembuatan aplikasi perangkat lunak ini, terlebih dahulu adalah menentukan dan merencanakan kriteria-kriteria dalam penentuan PUPUK NON SUBSIDI kemudian selanjutnya membuat alur sistem kerja perangkat lunak yang akan dibuat dengan merancang alur system yang akan dibuat kemudian setelah alur nya bener-bener dibuat maka masuklah ke tahap perancangan design menu yang akan di tampilkan agar user dan pengguna dapat lebih memahami kemana arah system yang dibuat selanjutnya masuk ketahapan pbahasa pemrograman yang dibuat yaitu masuk kebahasa pemrograman PHPkarena lebih mudah difahami setelah pembuatan bahasa pemrigarman maka selanjutnya lagi masuk ketahapan pembuatan Database yaitu tempat penyimpanan semua data. Setelah selesai pembuatan database maka selesai lah perancangan pembuatan program aplikasi mengenai pupuk non subsidi tersebut.

\section{Pemodelan}

Flowchart Sistem

\section{Gambar 1. Flowchart Sistem}

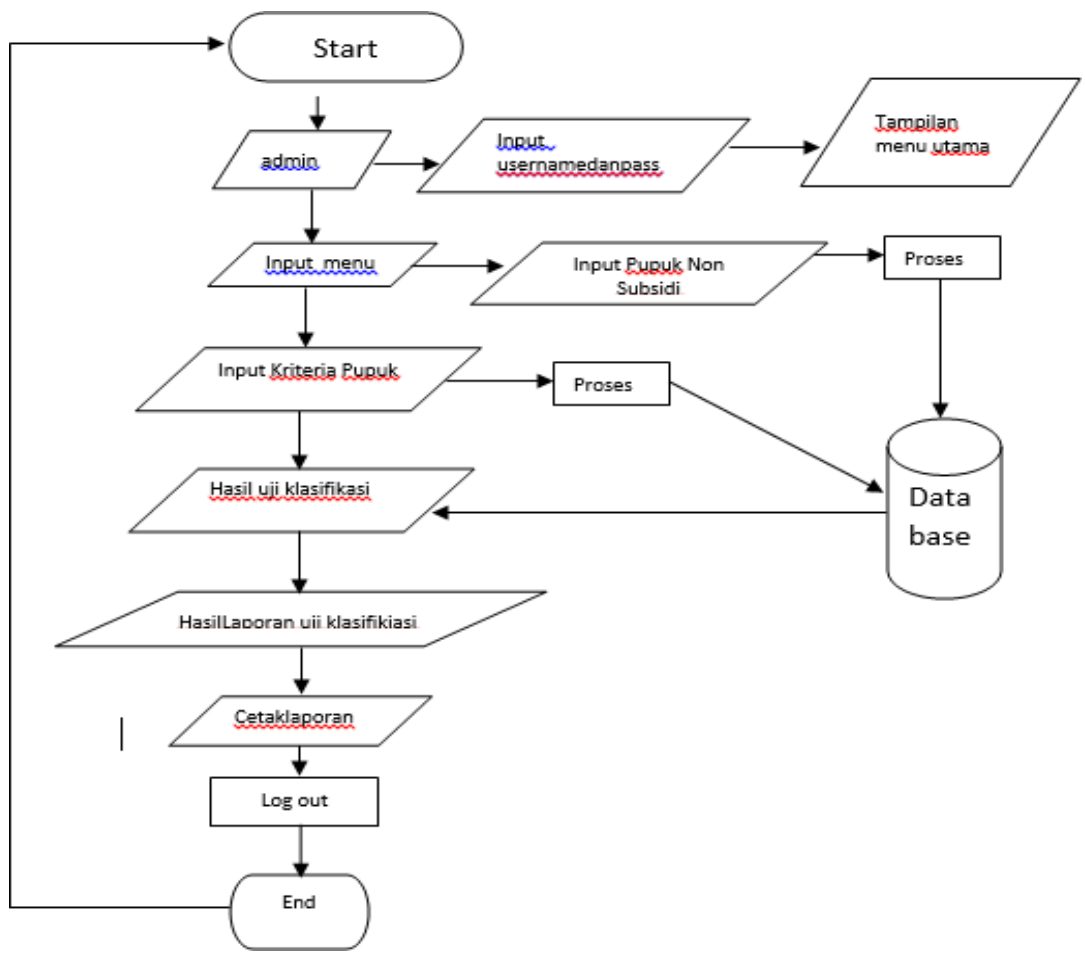

Perancangan Antarmuka Percangan Input

Gambar 2. Menu Login

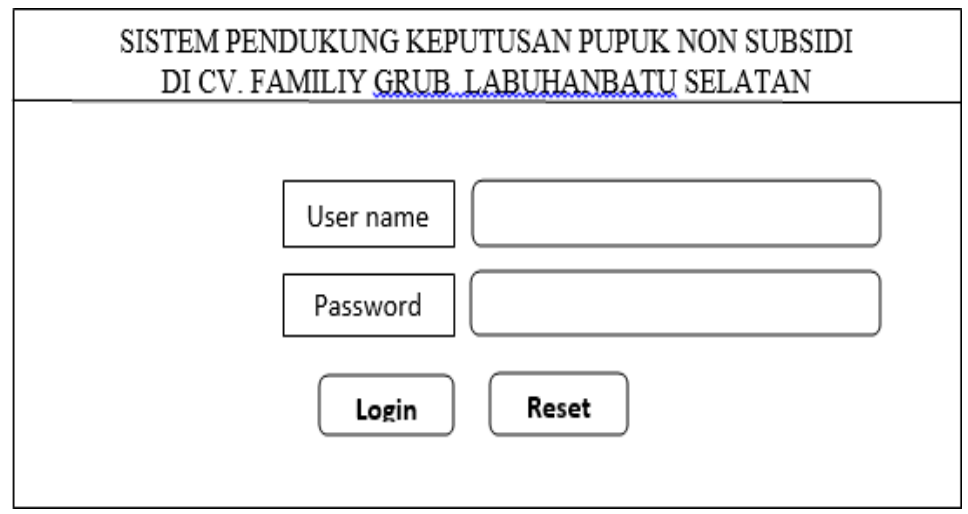


Perancangan Menu Utama

Gambar 3. Menu Utama

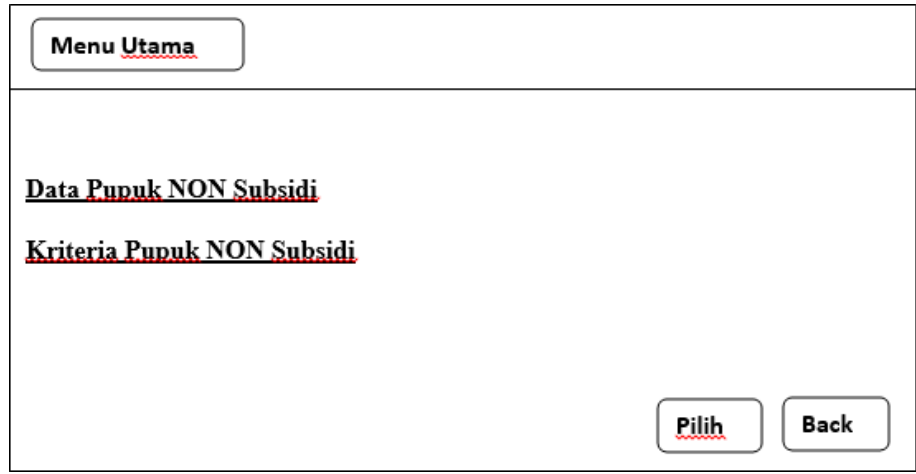

Percangan Menu Data Pupuk NON Subsidi

Gambar 4. Data Pupuk NON Subsidi

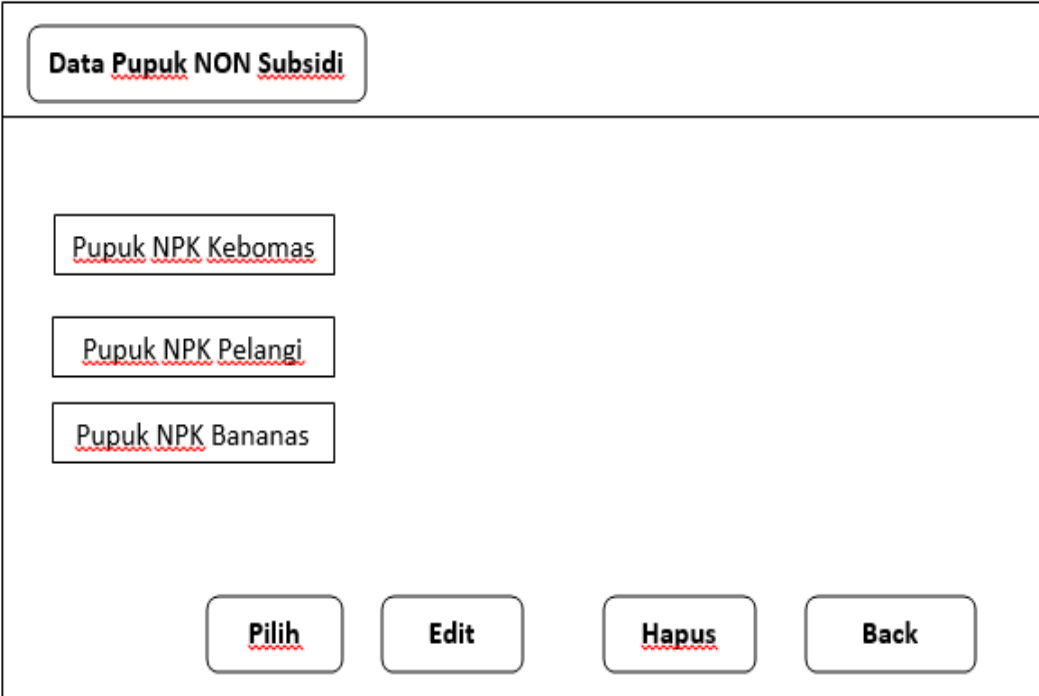

Percangan Output Hasil Laporan

Gambar 5. Tampilan Output Laporan

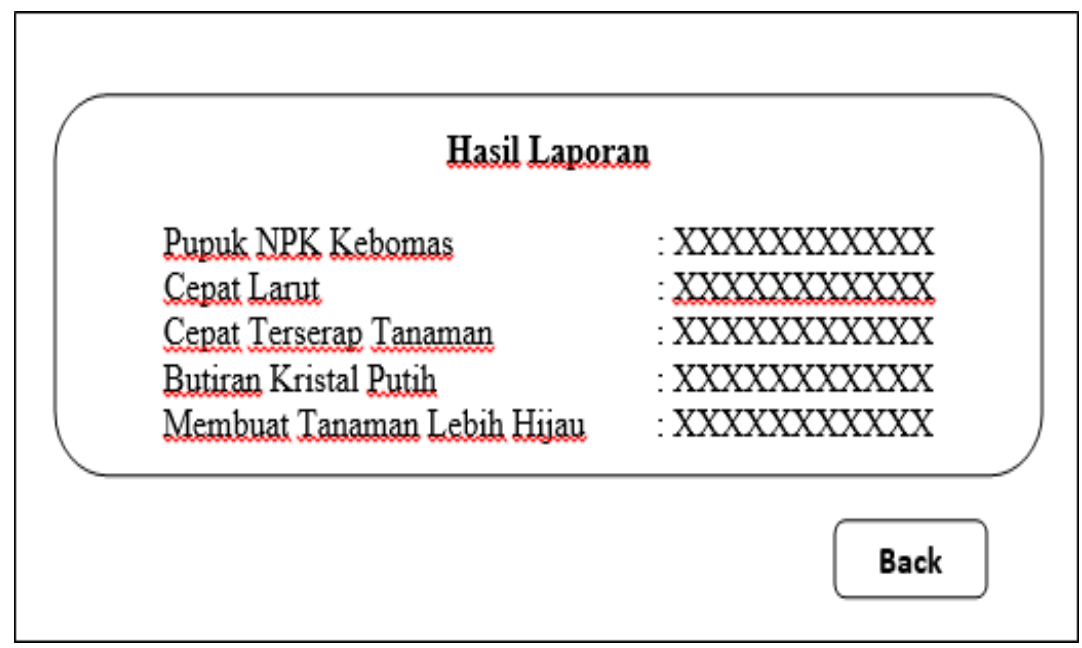


Tampilan Program Tampilan Login Admin

Gambar 6. Login Admin

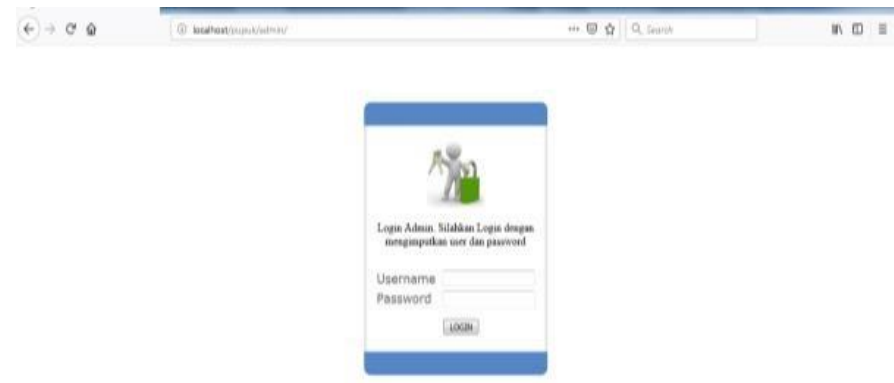

Tampilan Halaman Admin

Gambar 7. Halaman Admin

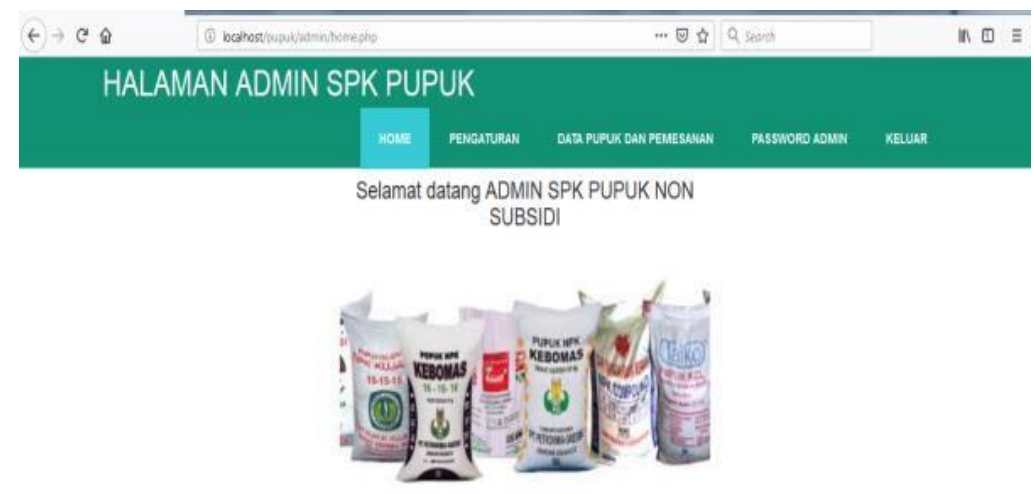

Tampilan Halaman Laporan Data Pemesanan Pupuk

Gambar 8 Halaman Laporan Data PemesananPupuk

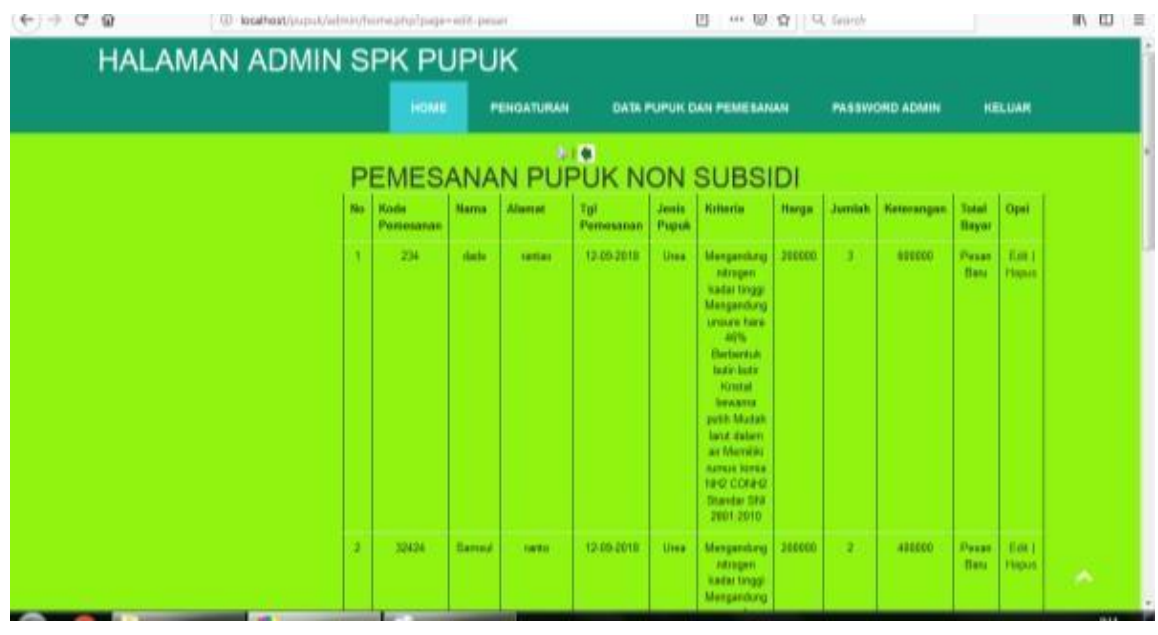

U-NET Jurnal Teknik Informatika, Vol. 03, No. 01, Februari 2019: 14-20 


\section{KESIMPULAN DAN SARAN}

\section{Kesimpulan}

Untuk menjadikan rangkuman dari pembuatan aplikasi sistem pendukung keputusan pemilihan pupuk non subsidi ini penulis mengambil beberapa kesimpulan, yaitu:

a. Bahwa aplikasi sistem pendukung keputusan pemilihan pupuk non subsidi ini menyediakan pemesanan pupuk.

b. Aplikasi sistem pendukung keputusan pemilihan pupuk non subsidi ini juga dalam hasil laporan nya berbentuk diatas kertas atau dengan hasil print laporan.

\section{Saran}

Untuk menjadikan bahan evaluasi dalam pengembangan apliaksi sistem pendukung keputusan pemilihan pupuk non subsidi, ada beberapa saran dan masukan, diantaranya adalah:

a. Agar bisa menambahkan jenis pupuk yang bersubsidi tidak hanya pupuk yang non subsidi saja

b. Dan juga menambahkan menu pupuk tanaman yang lebih terperinci lagi agar pemesan dapat mengtahui jenis pupuk non subsidi yang dipesan untuk tanaman apa.

\section{REFERENSI}

[1] F. Edi, P. T. Informatika, and F. U. A. Labuhanbatu, "UNET | Jurnal Ilmiah Teknik Informatika LPPM Universitas Al Washliyah Labuhanbatu UNET | Jurnal Ilmiah Teknik Informatika ISSN . 2460-3694, Vol . 2 No . 1 Februari 2018," vol. 2, no. 1, pp. 2-5, 2018.

[2] D. I. G. H. Wirhan Fahrozi, Samsir, "Penerapan E-Commerce Pada Toko Bunga Underwear," J. Tek. Inform., vol. 04, no. 01, pp. 1-6, 2020.

[3] S. Samsir, S. Suparno, and M. Giatman, "Predicting the loan risk towards new customer applying data mining using nearest neighbor algorithm," IOP Conf. Ser. Mater. Sci. Eng., vol. 830, no. 3, 2020, doi: 10.1088/1757-899X/830/3/032004.

[4] R. A. Purba, S. Samsir, M. Siddik, S. Sondang, and M. F. Nasir, "The optimalization of backpropagation neural networks to simplify decision making," IOP Conf. Ser. Mater. Sci. Eng., vol. 830, no. 2, 2020, doi: 10.1088/1757-899X/830/2/022091.

[5] W. Fahrozi, P. T. Informatika, T. Informatika, F. U. A. Labuhanbatu, T. Mulia, and K. Medan, "UNET : Jurnal Teknik Informatika LPPM - Universitas Al Washliyah Labuhanbatu $23 \mid$ P a g e UNET : Jurnal Teknik Informatika Sebagai langkah awal yang dilakukan supaya dapat mengetahui gambaran permasalahan yang dihadapi dalam menentukan rasa yam serama a," vol. 3, no. 5, pp. 2327, 2019.

[6] Samsir, "Klasifikasi Penyakit Tenggorokan Hidung Telinga ( THT ) Menggunakan Jaringan Syaraf Tiruan Dengan Metode Learning Vektor Quantization ( THT ) Di RSUD Rantauprapat Labuhanbatu Klasifikasi penyakit Tenggorokan Hidung Telinga ( THT ) Menggunakan,” vol. 05, no. 01, pp. 3847, 2019.

[7] D. Indra et al., "SPK Untuk Pemilihan Kepala Sekolah Menggunakan Metode Saw dan Profile Matching," vol. 4, no. 1, pp. 7-12, 2020.

[8] P. T. Informatika and F. U. A. Labuhanbatu, "U-NET : Jurnal Teknik Informatika LPPM Universitas Al Washliyah Labuhanbatu 18 | P a g e U-NET : Jurnal Teknik Informatika Sebagai langkah awal yang dilakukan supaya dapat mengetahui gambaran permasalahan yang dihadapi oleh bagian kesiswaan adalah denga," vol. 3, no. 4, pp. 18-22, 2019.

[9] M. Siddik and S. Samsir, "Rancang Bangun Sistem Informasi Pos (Point of Sale) Untuk Kasir Menggunakan Konsep Bahasa Pemrograman Orientasi Objek," JOISIE (Journal Inf. Syst. Informatics Eng., vol. 4, no. 1, p. 43, 2020, doi: 10.35145/joisie.v4i1.607.

[10] Samsir and Syaiful Zuhri Harahap, "Application Design Resume Medical By Using Microsoft Visual Basic. Net 2010 At the Health Center Appointments,” Int. J. Sci. Technol. Manag., vol. 1, no. 1, pp. 14-20, 2020, doi: 10.46729/ijstm.v1i1.5.

[11] M. V. B. Net, "PADA TOKO URIP MOTOR," no. September, pp. 1-6, 2020.

[12] Samsir, D. I. G. Hts, and S. Z. Harahap, "SPK Untuk Pemilihan Kepala Sekolah Menggunakan Metode Saw dan Profile Matching," U-NET J. Tek. Inform., 2020.

[13] J. H. P. Sitorus et al., "Perancangan pengontrol lampu rumah miniatur dengan menggunakan micro controler arduino berbasis android 1," vol. 4, no. 1, pp. 1-11, 2020. 
[14] U. Verawardina, F. Edi, and R. Watrianthos, “Analisis Sentimen Pembelajaran Daring Pada Twitter di Masa Pandemi COVID-19 Menggunakan Metode Naïve Bayes,” vol. 5, pp. 157-163, 2021, doi: 10.30865/mib.v5i1.2604.

[15] S. Zulkifli, "Implementasi Sistem Keamanan SQL Injection Dalam berbasis web," Ejurnal.Univalabuhanbatu.Ac.Id, vol. 04, no. 01, pp. 13-17, 2020, [Online]. Available: https://ejurnal.univalabuhanbatu.ac.id/index.php/u-net/article/download/164/130.

[16] Syaiful Zuhri Harahap and Samsir, "Application Design The Data Collection Features of The Hotel Shades of Rantauprapat Using VBNET,” Int. J. Sci. Technol. Manag., 2020, doi: 10.46729/ijstm.v1i1.4.

[17] R. Watrianthos, Y. Triyanto, P. Pristiyono, D. Hasibuan, and S. Samsir, "e-Government Village Model," 2020, doi: 10.4108/eai.11-12-2019.2290857. 